\title{
Histone Deacetylase Inhibitors Prevent p53-Dependent and p53-Independent Bax-Mediated Neuronal Apoptosis through Two Distinct Mechanisms
}

\author{
Takuma Uo, ${ }^{1}$ Timothy D. Veenstra, ${ }^{2}$ and Richard S. Morrison ${ }^{1}$ \\ ${ }^{1}$ Department of Neurological Surgery, University of Washington School of Medicine, Seattle, Washington 98195-6470, and ${ }^{2}$ Laboratory of Proteomics and \\ Analytical Technologies, Science Applications International Corporation-Frederick, Inc., National Cancer Institute at Frederick, Frederick, Maryland 21702- \\ 1201
}

\begin{abstract}
Pharmacological manipulation of protein acetylation levels by histone deacetylase (HDAC) inhibitors represents a novel therapeutic strategy to treat neurodegeneration as well as cancer. However, the molecular mechanisms that determine how HDAC inhibition exerts a protective effect in neurons as opposed to a cytotoxic action in tumor cells has not been elucidated. We addressed this issue in cultured postnatal mouse cortical neurons whose p53-dependent and p53-independent intrinsic apoptotic programs require the proapoptotic multidomain protein, Bax. Despite promoting nuclear p53 accumulation, Class I/II HDAC inhibitors (HDACIs) protected neurons from p53-dependent cell death induced by camptothecin, etoposide, heterologous p53 expression or the MDM2 inhibitor, nutlin-3a. HDACIs suppressed p53-dependent PUMA expression, a critical signaling intermediate linking p53 to Bax activation, thus preventing postmitochondrial events including cleavage of caspase-9 and caspase-3. In human SH-SY5Y neuroblastoma cells, however, HDACIs were not able to prevent p53-dependent cell death. Moreover, HDACIs also prevented caspase-3 cleavage in postnatal cortical neurons treated with staurosporine, 3-nitropropionic acid and a Bcl-2 inhibitor, all of which require the presence of Bax but not p53 to promote apoptosis. Although these three toxic agents displayed a requirement for Bax, they did not promote PUMA induction. These results demonstrate that HDACIs block Bax-dependent cell death by two distinct mechanisms to prevent neuronal apoptosis, thus identifying for the first time a defined molecular target for their neuroprotective actions.
\end{abstract}

\section{Introduction}

Histone deacetylase (HDAC) inhibitors are emerging as a new class of anticancer agent capable of altering critical functions in tumor cells through epigenetic changes in gene expression (Bolden et al., 2006; Dokmanovic et al., 2007). Mammals have four families of HDACs; Class I, II and IV enzymes require zinc for catalytic activity, whereas class III enzymes are nicotinamide adenine dinucleotide dependent (Bolden et al., 2006; Dokmanovic et al., 2007). The opposing actions of these HDACs and histone acetyltransferases (HAT) dictate the patterns of gene expression through regulated acetylation of histones and/or nonhistone proteins including signal transducers and transcription factors. Thus, any imbalance in the HAT/HDAC system could potentially alter cellular homeostasis. Indeed, abnormalities in the regulation of HAT/HDAC expression/activity have been associated with tumorigenesis and, more recently, with neurodegenerative diseases (Bolden et al., 2006; Saha and Pahan, 2006;

Received Dec. 30, 2008; revised Jan. 29, 2009; accepted Jan. 30, 2009

This work was supported by National Institutes of Health Grants NS35533 and NS056031 to R.S.M. We acknowledge Drs. Yoshito Kinoshita and Sean P. Murphy at the University of Washington for thoughtful discussions of the data, Matthew L. Batten for technical assistance, and Bonita Lee for genotyping. Microarray analysis was performed at the Microarray Facility at the Center for Ecogenetics and Environmental Health (University of Washington).

Correspondence should be addressed to Dr. Richard S. Morrison, Department of Neurological Surgery, University of Washington School of Medicine, Box 356470, Seattle, WA 98195-6470. E-mail: yael@u.washington.edu.

D0I:10.1523/JNEUROSCI.6186-08.2009

Copyright $\odot 2009$ Society for Neuroscience $\quad$ 0270-6474/09/292824-09\$15.00/0
Dokmanovic et al., 2007). HDAC inhibitors (HDACIs) can mitigate the phenotypes associated with polyglutamine diseases including Huntington's disease (HD) (Steffan et al., 2001; Hockly et al., 2003; Gardian et al., 2005) and spinal and bulbar muscular atrophy (Minamiyama et al., 2004) as well as nonpolyglutamine neurodegenerative diseases such as amyotrophic lateral sclerosis (ALS) (Ryu et al., 2005; Petri et al., 2006). However, the neuroprotective actions of HDAC inhibitors observed in these disparate models of neurodegeneration remain poorly characterized.

The tumor suppressor protein, p53, coordinates cell-cycle progression and apoptosis through transcription-dependent and transcription-independent mechanisms (Vousden and Lane, 2007). In the CNS, the absence or inhibition of p53 activity protects neurons in vivo and in vitro from both acute neurological insults (Morrison et al., 2003) as well as chronic neurodegenerative diseases as recently demonstrated in a mouse model of HD (Bae et al., 2005). These collectively point to p53 as a potential clinical target for neurodegenerative disease therapy.

Given the evidence of p53 involvement in HD and other neurodegenerative diseases, coupled with the neuroprotective effects of HDAC inhibitors in animal models of these diseases, we reasoned that HDAC inhibitor-sensitive components might participate in p53-mediated cell death signaling in neurons. We report here that HDACIs specific for class I and II HDACs prevent p53dependent neuronal apoptosis through selective suppression of p53-target genes and consequent abrogation of Bax activation. 
We further demonstrate that HDACIs prevent BAX-dependent caspase-3 cleavage under conditions that do not require p53. These findings suggest that HDACIs may protect neurons from a diverse array of neurological insults by blocking both p53dependent and p53-independent pathways and provide a molecular framework for understanding neuroprotective HDACI action in neurons.

\section{Materials and Methods}

Materials. Trichostatin A (TSA), etoposide, nicotinamide, Bcl-2 inhibitor and sirtinol were purchased from EMD Biosciences. Sodium butyrate (SB) was from Sigma-Aldrich. Suberoylanilide hydroxamic acid (SAHA) was obtained from BioVision. The sources for other chemicals are described previously (Xiang et al., 1998; Johnson et al., 1999; Uo et al., 2007).

Cell culture and adenovirus infection. SH-SY5Y human neuroblastoma cells were maintained in Dulbecco's modified MEM/F12 (1:1) with 10\% fetal bovine serum and treated as described previously (Johnson et al., 1999; Uo et al., 2005). Primary neuronal cultures derived from postnatal day 0 ( $\mathrm{P} 0)$ cortex were prepared as described previously (Xiang et al., 1996) and maintained for 3 or $4 \mathrm{~d}$ before experimental manipulations unless otherwise specified. Cell viability was determined based on morphological criteria as described previously (Xiang et al., 1996), by green fluorescent protein (GFP) fluorescence or nuclear staining with ethidium homodimer-1 (EthD-1). Dying or dead cells at $24 \mathrm{~h}$ after treatment were visualized by incubation with $2 \mu \mathrm{M}$ EthD- 1 for $30 \mathrm{~min}$ at room temperature.

To express $\mathrm{p} 53$ in $\mathrm{p} 53^{-/-}$postnatal cortical neurons, 1-d-old cultures were infected with adenovirus carrying the human p53 gene (Ad-p53) or the $\beta$-galactosidase gene (Ad-LacZ), propagated as described previously (Xiang et al., 1996), at $50 \mathrm{MOI}$ for $24 \mathrm{~h}$, followed by the specified treatment for $12 \mathrm{~h}$.

Plasmid construction and transient transfection assay. cDNA fragments encoding mouse $p 21^{W A F 1 / C I P 1}$ and $B I M_{E L}{ }_{L}$ and ${ }_{S}$ were prepared by RTPCR using the OneStep RT-PCR kit (Qiagen) using total RNA isolated from mouse cortical neuronal cultures. The following primers were used for $p 21^{W A F 1 / C I P 1}$ (forward primer, GGG AAT TCA TGT CCA ATC CTG GTG ATG TCC; reverse primer, GGA CTC GAG TCA GGG TTT TCT CTT GCA GAA GAC) and for $B I M_{E L},{ }_{L}$ and ${ }_{S}$ (forward primer, GGA GAA TTC ATG GCC AAG CAA CCT TCT GAT GTA AG; reverse primer, GGA CTC GAG TCA ATG CCT TCT CCA TAC CAG ACG). EcoRI and XhoI sites are singly and doubly underlined, respectively. Each resultant PCR fragment was digested with EcoRI and XhoI and subsequently cloned into the same site of the pCMVTag2B vector (Stratagene) for $\mathrm{p} 21^{\mathrm{WAF} 1 / \mathrm{CIP} 1}$ and pCDNA3 FLAG vector (Uo et al., 2005, 2007) for BIM isoforms. For transient transfection assays, $1 \mathrm{~d}$ after plating, postnatal cortical neurons plated in 4-well multidishes (Nunc) at $4 \times 10^{5}$ cells/well were cotransfected with $0.2 \mu \mathrm{g}$ of a GFP expression vector (pEGFPN2; BD Biosciences, Clontech) and $0.8 \mu \mathrm{g}$ of the expression plasmid for $\mathrm{p} 21^{\mathrm{WAF} 1 / \mathrm{CIP} 1}$ (pCMVTag2 $\mathrm{p} 21^{\mathrm{WAF} 1 / \mathrm{CIP} 1}$ ) or for BIM isoforms (pCDNA3 FLAG BIM ${ }_{\mathrm{EL}}$, $_{\mathrm{L}}$ and ${ }_{\mathrm{S}}$ ) using Lipofectamine 2000 (Invitrogen) as described previously (Uo et al., 2007).

Caspase-3 enzymatic activity assay. Caspase- 3 enzymatic activity was determined by monitoring the cleavage of the fluorogenic caspase substrate zDEVD-AFC using the Caspase-3 Assay Kit (BD Biosciences) as described previously (Johnson et al., 1999).

Immunoblotting, immunoprecipitation and immunofluorescence. Preparation of protein extracts, Western blotting and immunoprecipitation for detecting the activated form of Bax were performed as described previously (Uo et al., 2005, 2007). Fluorescence and phase-contrast microscopic images were captured on an Axiovert 200 inverted microscope (Carl Zeiss Microimaging) equipped with a cooled charge-coupled device camera (SensiCam, Cooke Corporation). Images to be directly compared were processed in an identical manner with Slidebook imaging software (Intelligent Imaging Innovations). The sources of the antibodies used and the respective dilutions are given in supplemental Table 1, available at www.jneurosci.org as supplemental material.

Microarray and semiquantitative RT-PCR analyses. Microarray data were obtained and analyzed as described previously (Uo et al., 2007). Semiquantitative RT-PCR was performed as described previously with the primers described previously (Uo et al., 2007) or listed in supplemental Table 1, available at www.jneurosci.org as supplemental material. Briefly, reverse transcription was performed at $55^{\circ} \mathrm{C}$ for $30 \mathrm{~min}$ followed by a $15 \mathrm{~min}$ denaturation step at $94^{\circ} \mathrm{C}$. This was followed by 30 cycles at $94^{\circ} \mathrm{C}$ for $30 \mathrm{~s}, 55^{\circ} \mathrm{C}$ for $30 \mathrm{~s}$, and $72^{\circ} \mathrm{C}$ for $30 \mathrm{~s}$. A serial dilution of total RNA (0.02-50 ng in $20 \mu \mathrm{l}$ of reaction mixture) was used to determine an appropriate amount of RNA for each gene to obtain the linear range of amplification. The amount of total RNA thus determined was as follows: PUMA, 0.4 ng; cyclin G1, 0.4 ng; $21^{\text {WAF1/CIP1 }}$, GTSE1, 2 ng; PHLDA3, 0.1 ng; RPS12, $0.1 \mathrm{ng}$.

\section{Results}

\section{Class I and II HDACIs block p53-dependent neuronal apoptosis distal to $\mathrm{p} 53$ accumulation but proximal to Bax activation}

In mouse postnatal cortical neurons, the topoisomerase I inhibitor camptothecin (CPT) causes DNA damage and induces p53 expression and transcriptional activation of the $\mathrm{BH} 3$-only protein PUMA, which results in Bax-dependent caspase- 3 activation and extensive cell death within 24 h (Uo et al., 2007). Genetic ablation of either p53 or Bax completely blocks caspase- 3 activation and cell death (Xiang et al., 1998; Uo et al., 2007), while either knockout (Cregan et al., 2004) or knockdown (Uo et al., 2007) of PUMA provides significant protection from p53dependent neuronal death. In this CPT-induced p53-dependent apoptosis model, cell death was completely blocked by structurally distinct HDACIs, such as the short-chain fatty acid SB and the hydroxamic acid TSA based on morphological assessment (Fig. 1A, $B$; supplemental Fig. 1, available at www.jneurosci.org as supplemental material). The protection conferred by TSA was also validated by a functional assay using ethidium homodimer, which can only penetrate damaged cells and stain their nuclear DNA (supplemental Fig. 1, available at www.jneurosci.org as supplemental material). In contrast, the sirtuin (class III HDAC) inhibitor, nicotinamide, failed to show protection (supplemental Fig. 2A, available at www.jneurosci.org as supplemental material).

Since postnatal cortical neurons are fully committed to undergo apoptosis by $12 \mathrm{~h}$ after CPT exposure (Uo et al., 2007), this time point was chosen to identify HDACI-sensitive biochemical pathways that promote neuronal apoptosis. By $12 \mathrm{~h}$, DNA damage-induced p53 nuclear accumulation has become evident (Fig. 1C). TSA did not block, but rather enhanced, total and nuclear accumulation of p53 in response to DNA damage (Fig. $1 C, D)$. Despite the dramatic increase in p53 levels, TSA almost completely blocked p53-dependent caspase-3 activation and caspase-3 enzymatic activity induced in response to CPT (Fig. $1 D, E$ ). Similar results were obtained for SB and SAHA (supplemental Fig. 2C,D, available at www.jneurosci.org as supplemental material). Consistent with its lack of neuroprotective activity based on morphological criteria (supplemental Fig. $2 \mathrm{~A}$, available at www.jneurosci.org as supplemental material), nicotinamide (sirtuin inhibitor) did not block caspase-3 activation (supplemental Fig. $2 B$, available at www.jneurosci.org as supplemental material). The neuroprotective action of HDACIs against p53mediated cell death was further validated using a second class of DNA damaging agent, the topoisomerase II inhibitor etoposide. As observed with CPT, etoposide upregulated p53 protein levels and induced caspase- 3 activation which was completely blocked by either TSA treatment (Fig. $1 F$ ) or p53 deficiency (data not shown).

HDACIs also blocked p53-mediated cell death induced with- 

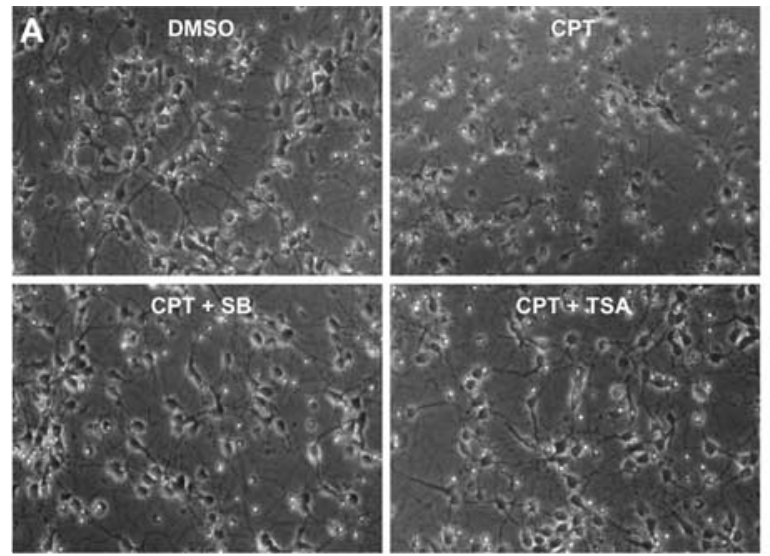

E

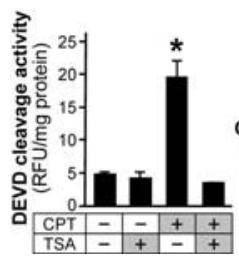

$\mathbf{F}$

G
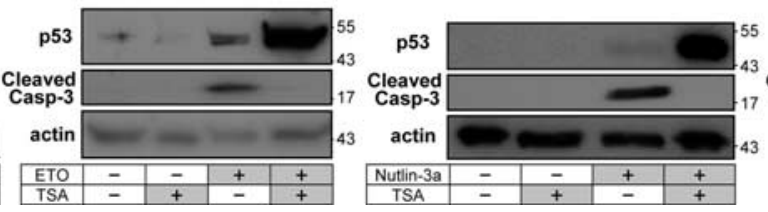
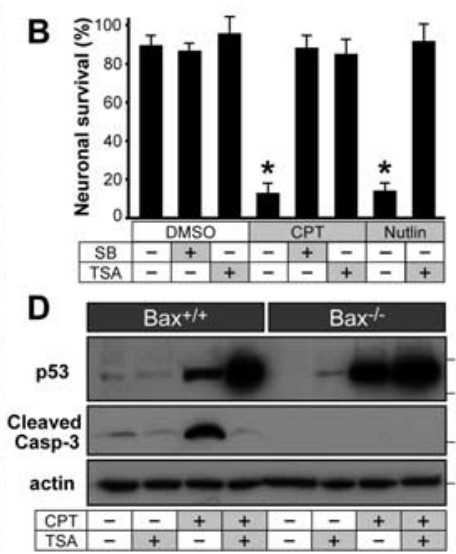

H

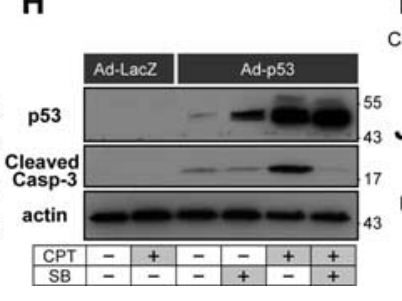

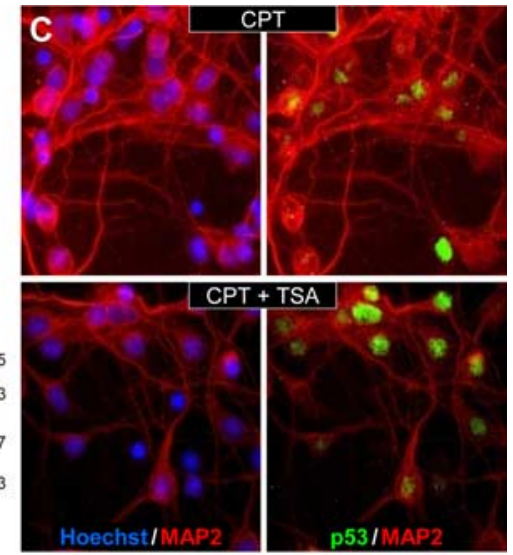

I

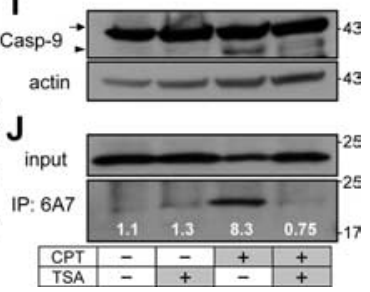

Figure 1. HDACls prevent p53-mediated neuronal apoptosis through inhibition of the p53-Bax pathway. $A$, HDACls protect against camptothecin-induced neuronal cell death. p53 ${ }^{+/+}$neurons were treated with CPT $(2.5 \mu \mathrm{M})$ alone or in combination with SB $(2 \mathrm{~mm})$ or TSA $(200 \mathrm{~nm})$ with DMSO used as a vehicle control. Representative phase-contrast images at $24 \mathrm{~h}$ after treatment are shown. $B$, Neuronal survival was quantitatively assessed by morphology (Xiang et al., 1996), by counting healthy cells in the same field at time 0 and $24 \mathrm{~h}$ after treatment for each condition as shown in supplemental Figure $3 A$, available at www.jneurosci.org as supplemental material. Mean \pm SD of two fields each from three cultures ( $n=6$; results confirmed in 3 independent experiments). Asterisk indicates significantly different from all other conditions ( $p<0.0001$, one-way ANOVA using Tukey's post hoc test). Other comparisons between the conditions show no significant difference $(p>0.05)$. C, Effect of TSA on $p 53$ expression. $p 53^{+/+}$neurons were treated with CPT and/or TSA for $12 \mathrm{~h}$, fixed and stained for p53 and a neuronal marker, MAP2, with Hoechst 33258 staining. Representative images are shown from three independent experiments. D, Effect of TSA on p53 and cleaved caspase-3 protein levels. Protein samples were prepared from Bax ${ }^{+/+}$and $\mathrm{Bax}^{-I-}$ neurons treated with CPT and/or TSA for $12 \mathrm{~h}$ and subjected to Western blotting. $\beta$-Actin was used as an internal loading control for all blots unless otherwise stated. Representative data are shown from two independent experiments. $\boldsymbol{E}$, HDACl treatment reduces caspase cleavage activity. $\mathrm{p5} 3^{+/+}$neurons were harvested at $12 \mathrm{~h}$ after treatment with CPT and/or TSA (DMSO as a vehicle control). Cytosolic extracts were prepared and evaluated for zDEVD-AFC cleavage activity. The data represent the mean $\pm S D$ of relative fluorescence units (RFU)/mg protein ( $n=3$ cultures per condition; results confirmed in 3 independent experiments). Asterisk indicates significantly different from all other conditions ( $p<0.0001$, one-way ANOVA using Tukey's post hoc test). DMSO versus CPT plus TSA, $p=0.63$. Other comparisons between the conditions showed no significant difference $(p>0.05)$. $\boldsymbol{F}$, TSA blocks etoposide (ET0)-induced caspase-3 cleavage. p53 ${ }^{+/+}{ }^{\text {neurons }}$ were treated with ETO $(5 \mu \mathrm{M})$ and/or TSA $(200 \mathrm{~nm})$ for $12 \mathrm{~h}$ and analyzed by Western blotting as described in $\boldsymbol{D}$. Representative data are shown from two independent experiments. $\boldsymbol{G}$, TSA blocks caspase-3 cleavage induced by Nutlin-3a. $553^{+/+}$neurons were treated with nutlin-3a $(10 \mu \mathrm{M})$ and/or TSA ( $\left.200 \mathrm{~nm}\right)$. Protein samples were prepared $12 \mathrm{~h}$ after treatment and analyzed for $\mathrm{p} 53$ and cleaved caspase-3. Representative data are shown from two independent experiments. $\boldsymbol{H}, \mathrm{HDACl}$ blocks caspase-3 activation induced by heterologous expression of human p53. $553^{-1-}$ neurons were infected with adenovirus expressing human p53 (Ad-p53) or $\beta$-galactosidase (Ad-LacZ) at $50 \mathrm{MOl}$ for $24 \mathrm{~h}$ and then, after washing with virus-free media, treated with (PT (2.5 $\mu \mathrm{m}$ ) in the presence or absence of SB $(2 \mathrm{~mm})$. DMSO was used as a vehicle control. Cellular exacts were prepared $12 \mathrm{~h}$ after treatment and analyzed for total p53 protein and cleaved caspase-3. Representative data are shown from two independent experiments. $I$, TSA blocks caspase- 9 cleavage induced by CPT treatment. $p 53^{+/+}$neurons were treated with CPT and/or TSA. Protein samples were prepared $12 \mathrm{~h}$ after treatment and analyzed for caspase-9. The arrow and arrowhead indicate full-length and cleaved caspase-9, respectively. Representative data are shown from two independent experiments. J, TSA blocks Bax activation induced by CPT treatment. $\mathrm{p} 53^{+/+}$neurons were treated with (PT and/or TSA (DMSO as vehicle control) for $12 \mathrm{~h}$, then lysed and subjected to immunoprecipitation with anti-Bax (6A7) antibody for detecting activated Bax protein. Total extracts (input) and immune complexes (IP: 6A7) were analyzed by Western blotting using anti-Bax (N-20) antibody. The intensity of each band corresponding to the Bax protein was quantitated using ImageJ 1.410 software (National Institutes of Health, Bethesda, MD). The data are presented as the ratio of the immunoprecipitated Bax band relative to the respective Bax input signal. Representative data are shown from three independent experiments.

out DNA damage. Nutlin-3a is a chemical that promotes p53 accumulation by antagonizing Mdm2 (Vassilev et al., 2004), inducing p53- and Bax-dependent caspase-3 activation and neuronal death (Uo et al., 2007). TSA further elevated p53 protein levels but blocked neuronal death induced by nutlin-3a (Fig. 1B, G; supplemental Fig. 3A, available at www.jneurosci.org as supplemental material). We also determined if HDACIs could block caspase- 3 activation induced by heterologous expression of human p53. We previously showed that human p53 expressed in p53-deficient neurons at low levels does not induce cell death on its own but can mediate cell death induced by CPT (Uo et al., 2007). Under these conditions, CPT induced caspase- 3 activation only in the presence of exogenous human $\mathrm{p} 53$, which was blocked by cotreatment with SB or TSA (Fig. $1 H$; supplemental Fig. $3 B$, available at www.jneurosci.org as supplemental material).

HDACIs are known to change the expression levels of proapoptotic and antiapoptotic multidomain Bcl-2 family pro- teins (Doi et al., 2004; Hajji et al., 2008). In CPT-treated cortical neurons, however, TSA cotreatment did not induce significant changes in the expression levels of $\mathrm{Bcl}-\mathrm{x}_{\mathrm{L}}, \mathrm{Bcl}-2$ and Bax [BAK is not expressed in neurons (Uo et al., 2005)] regardless of p53 status, suggesting that this mechanism of action is not involved in neuroprotection in this model (supplemental Fig. 3C, available at www.jneurosci.org as supplemental material). However, TSA blocked CPT-induced cleavage of caspase-9, which requires formation of the apoptosome comprised of caspase-9, APAF1 and cytochrome $c$ released into the cytosol as a consequence of Bax- (neurons) or Bax/BAK (non-neuronal cells)-dependent mitochondrial outer membrane permeabilization (Riedl and Salvesen, 2007) (Fig. 1I). More importantly, although there was no increase in Bax expression, HDACI blocked the conformational Bax activation step, which is characterized by exposure of its $\mathrm{N}$ terminal 6A7 epitope (12-24 a.a.) (Fig. $1 J)$. These results collec- 

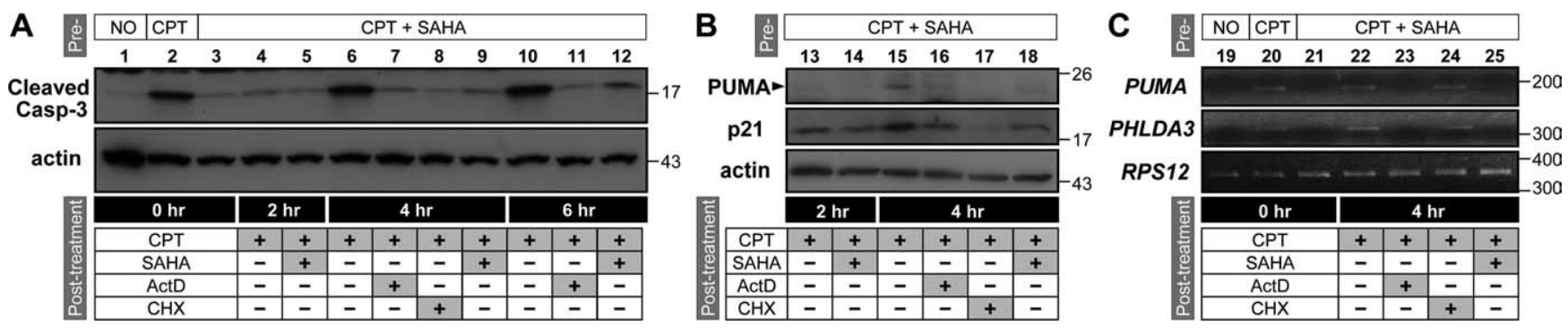

Figure 2. HDACls reversibly and selectively block p53-dependent transcriptional activation of PUMA. A, B, p53 ${ }^{+/+}$neurons were cotreated with CPT and SAHA (10 $\left.\mu \mathrm{M}\right)$ for $13 \mathrm{~h}$ ("Pre-" treatment) and then immediately harvested ( $0 \mathrm{~h}$ in "post-treatment") or provided fresh media with (PT, CPT plus SAHA, CPT plus actinomycin D (ActD; $2 \mu \mathrm{M}$ ), or CPT plus cycloheximide (CHX; 10 $\mu \mathrm{g} / \mathrm{ml})$, and then harvested at the indicated times after switching the media. DMSO was used as a vehicle control. Protein samples were analyzed for cleaved caspase-3 ( $\boldsymbol{A}$ ) and PUMA and p21 ${ }^{\text {WAF1/CIP1 }}$ (p21) (B) by Western blotting. Representative data are shown from two independent experiments. C, Expression levels of PUMA and PHLDA3 were analyzed by semiquantitative RT-PCR (see Materials and Methods) from total RNA extracted from cells collected at the indicated times after switching the initial media. Ribosomal protein S12 (RPS12) was analyzed as an internal control for RNA loading for each sample reaction. Representative data are shown from two independent experiments.

tively demonstrate that the sites of HDACI action reside between p53 activation and Bax activation.

\section{HDACIs selectively block p53-dependent transcription including the proapoptotic $\mathrm{BH} 3$-only protein, PUMA}

HDAC inhibition alters the expression of limited sets of genes and not only activates but also represses gene expression in a promoter-specific manner (Nusinzon and Horvath, 2005). Thus, we examined whether transcriptional modulation is involved in the neuroprotection conferred by HDACI treatment. CPTtreated neurons that were rescued by SAHA but would otherwise be committed to apoptosis were released from SAHA-protection in the presence or absence of transcription and translation inhibitors. In the continued presence of CPT, removal of SAHA (Fig. $2 A$, lane 6,10$)$ resulted in maximal caspase- 3 activation within $4 \mathrm{~h}$, while caspase- 3 activation remained suppressed in the presence of actinomycin D (lane 7,11 ) or cycloheximide (lane 8) similar to the levels seen in the continued presence of SAHA (lane $9,12)$. The fact that caspase- 3 activation triggered by SAHA removal completely depended on new mRNA and protein synthesis indicates that SAHA exerts its neuroprotective action by suppressing the expression of CPT-inducible proapoptotic genes. Although these results suggest that SAHA treatment may be inhibiting gene expression, the cyclin-dependent kinase inhibitor p21 WAFI/CIP1 , known to be induced by HDACIs (Langley et al., 2008) and to be protective (Morris et al., 2001) in embryonic neurons, was upregulated in TSA-treated neurons (supplemental Fig. $4 B, C$, available at www.jneurosci.org as supplemental material). However, transient overexpression of $\mathrm{p} 21^{\mathrm{WAF} 1 / \mathrm{CIP} 1} \mathrm{did}$ not attenuate CPT-induced neuronal death (supplemental Fig. 4D, available at www.jneurosci.org as supplemental material). The results are consistent with the idea that HDACIs exert an antiapoptotic effect by suppressing CPT-inducible transcriptional upregulation of certain proteins required for p53-dependent neuronal apoptosis.

This possibility was evaluated by determining if HDACIs affect the expression of p53 target genes using semiquantitative RT-PCR. CPT treatment induced p53-dependent increases in the transcripts of all the p53 target genes examined (PUMA, PHLDA3, GTSE1, p21 WAF1/CIP1, cyclin G1 and NOXA) (supplemental Fig. $4 B$, available at www.jneurosci.org as supplemental material). Intriguingly, PUMA expression was suppressed by cotreatment with HDACI (supplemental Figs. $4 B$, 5, available at www.jneurosci.org as supplemental material). Moreover, after release from protection by HDACI, the timing of PUMA induction correlated well with that of caspase-3 activation (Fig. $2 B, C$ ).
Importantly, transcriptional activation of PUMA did not require new protein synthesis after release from HDACI protection (Fig. $2 C)$. These data collectively demonstrate that HDAC inhibition directly represses the activity of the PUMA transcriptional complex. This finding is significant because the $\mathrm{BH} 3$-only protein PUMA represents an essential apoptosis mediator for neuronal apoptosis residing between $\mathrm{p} 53$ and Bax activation (Cregan et al., 2004; Wong et al., 2005; Uo et al., 2007). Thus, suppression of PUMA as a critical mediator of apoptosis in our CPT model of neuronal apoptosis (Uo et al., 2007) should account for a significant part of the neuroprotective actions of HDACIs and explains how Bax activation is blocked by HDACIs. We also identified PHLDA3, a gene involved in the extrinsic death receptor pathway (Park et al., 1996), as another p53 target gene (Jen and Cheung, 2005) whose $\mathrm{p} 53$-dependent induction was repressed by HDACIs (Fig. 2C; supplemental Fig. $4 A, B$, available at www.jneurosci.org as supplemental material). The other p53 target genes examined, including those that are involved in apoptosis regulation (GTSE1 and NOXA), remained unaffected by HDACI treatment.

During the course of investigating other $\mathrm{BH} 3$-only proteins in addition to PUMA, we unexpectedly found that HDACIs alone or in the presence of CPT significantly induced the largest protein isoform of the $\mathrm{BIM}$ protein, $\mathrm{BIM}_{\mathrm{EL}}$ (supplemental Fig. $6 A, B$, available at www.jneurosci.org as supplemental material) despite the fact that HDACIs did not kill neurons by themselves and protected them from CPT. Increased expression of all BIM isoforms $\left(\mathrm{BIM}_{\mathrm{EL}}, \mathrm{L}, \mathrm{s}\right)$ effectively killed cortical neurons in a Baxdependent manner (supplemental Fig. 6C, available at www. jneurosci.org as supplemental material), as reported for $\mathrm{BIM}_{\mathrm{EL}}$ in cerebellar granule neurons (Harris and Johnson, 2001), suggesting that HDACIs can abrogate the apoptotic action of BIM in cortical neurons. Collectively, these findings highlight the ability of HDACI's to selectively modify the expression and activity of p53 target gene products and $\mathrm{BH} 3$-only proteins in the context of neurons.

\section{HDAC inhibitors do not block p53-dependent cell death or caspase-3 activation in SH-SY5Y neuroblastoma cells} HDACIs are known to potentiate p53-dependent and p53independent apoptotic signaling in tumor cells (Bolden et al., 2006; Dokmanovic et al., 2007) in contrast to the neuroprotective effects we observed in neurons. Therefore, we used human SHSY5Y neuroblastoma cells to evaluate if HDAC inhibitors generally block p53-dependent death in cells of neuronal origin or if the effect is specific for postmitotic neurons. SH-SY5Y cells underwent p53-dependent apoptosis after CPT treatment 
(supplemental Fig. 7A, available at www. jneurosci.org as supplemental material), but unlike cortical neurons, TSA (200 nM) treatment did not block caspase-3 activity (Fig. $3 A$ ) or cell death (Fig. $3 B$ ). In fact, caspase enzyme activity was increased twofold by TSA in CPT-treated cells (Fig. $3 A)$. This apoptosis-promoting action of TSA does not involve a transcriptionindependent, mitochondria/cytosolassociated function of p53, since CPTinduced extranuclear accumulation of p53 remained negligible when cells were cotreated with TSA (supplemental Fig. $7 B$, available at www.jneurosci.org as supplemental material). Indeed, TSA prevented CPT-induced PUMA expression, while induction of another p53-target $\mathrm{BH} 3$-only protein NOXA was not affected (Fig. 3C). In contrast to its action in SH-SY5Y cells (Yakovlev et al., 2004), NOXA overexpression is not sufficient to promote cell death in postmitotic neurons such as cerebellar granule neurons (Cregan et al., 2004) and cortical neurons (Uo et al., 2007). Furthermore, siRNA-mediated depletion of NOXA reportedly protects SH-SY5Y cells from p53-dependent cell death induced by a DNA damaging agent (Yakovlev et al., 2004). These results strongly suggest that the proapoptotic molecule NOXA may determine the effects of HDACIs on p53induced apoptosis in different cell types.

\section{HDACIs prevent $\mathrm{p} 53$-independent but} Bax-dependent caspase- 3 activation in cortical neurons

While the results demonstrate that p53-dependent cell death signaling can be regulated by HDACIs in postmitotic neurons, they do not explain why HDACIs have neuroprotective actions in diverse models of neurodegenerative diseases. In addition to p53 signaling, other apoptotic signals modulate the expression/activity of proapoptotic and antiapoptotic $\mathrm{Bcl}-2$ family proteins which eventually leads to Bax/BAK-dependent permeabilization of the mitochondrial outer membrane (Youle and Strasser, 2008). Since postnatal cortical neurons lack the multidomain form of BAK (Uo et al., 2005), Bax represents the only critical regulator of mitochondrial integrity in these cells. Thus, we determined if HDACIs can block cell death that is independent of p53 but dependent on Bax. Staurosporine, a nonspecific protein kinase inhibitor, induced robust Bax-dependent activation of caspase- 9 and caspase- 3 independently of p53 (Fig. 4A,B; supplemental Fig. $8 A, B$, available at www.jneurosci.org as supplemental material). Cotreatment with HDACIs (TSA, SB or SAHA) completely blocked caspase- 3 activation, while sirtuin inhibitors, nicotinamide and sirtinol, were ineffective (Fig. 4A-C). Importantly, TSA completely blocked staurosporine-induced cleavage of caspase-9 (Fig. 4D). However, under the conditions evaluated, we did not observe significant changes in the expression of proteins required for apoptosome formation (cytochrome $c$ and APAF1) (supplemental Fig. 9A, available at www.jneurosci.org as supplemental material), which suggests that HDACIs act further upstream on the pathway connecting apoptotic signals with ap-
C
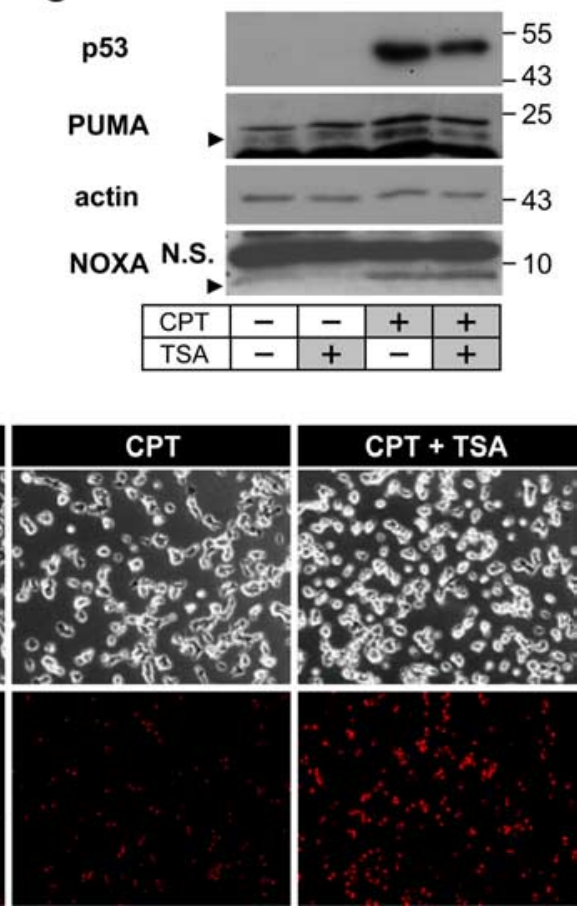

.

\section{TSA}

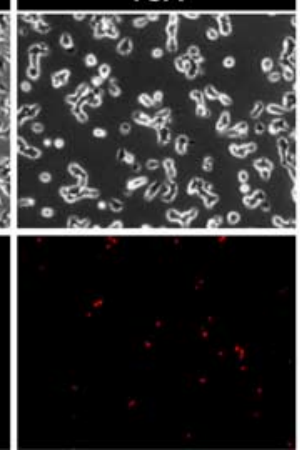

Figure 3. $\mathrm{HDACl}$ does not prevent p53-dependent caspase-3 activation and cell death in SH-SY5Y neuroblastoma. $\boldsymbol{A}$, SH-SY5Y cells were treated with (PT $(0.5 \mu \mathrm{m})$ and/or TSA (200 nM). DMSO served as a vehicle control. Cells were lysed for assessment of

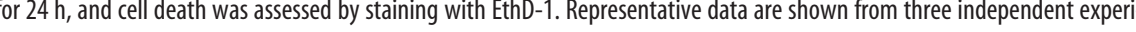
th gels. The nonspecific bands (N.S.) migrating at $\sim 12 \mathrm{kDa}$ on the NOXA blot provide an indication of protein loading. Representative data are shown from two independent experiments.

optosome formation. 3-Nitropropionic acid (3-NP) is an inhibitor of succinate dehydrogenase of mitochondrial complex II and its systemic administration causes Huntington's disease-like conditions that can be reversed by HDACIs (Ferrante et al., 2003). In our in vitro model, TSA blocked 3-NP-induced caspase-3 cleavage that occurred in a 553 -independent/Bax-dependent manner (Fig. $4 E$; supplemental Fig. $8 C$, available at www.jneurosci.org as supplemental material). We also used the small molecule Bcl-2 inhibitor, BCL2-I, which competes with a BAK BH3 peptide for binding to $\mathrm{Bcl}-2$ and $\mathrm{Bcl}-\mathrm{x}_{\mathrm{L}}$ (Enyedy et al., 2001) and thus directly precipitates an imbalance among Bcl-2 family member proteins. BCL2-I also produced p53-independent/Bax-dependent caspase-3 activation in cortical neurons (Fig. $4 F$; supplemental Fig. $8 D$, available at www.jneurosci.org as supplemental material), which was blunted by TSA treatment (Fig. $4 F$ ).

Higher concentrations of BCL2-I caused necrosis in a large population of neurons, which was completely prevented by the antioxidant glutathione but not by Bax deficiency or HDACIs (data not shown). Similarly, necrosis induced by $\mathrm{H}_{2} \mathrm{O}_{2}$ was not blocked by either Bax deficiency or HDACIs (data not shown). Necrotic signals initiate cell death by opening the mitochondrial permeability transition pore which does not require Bax as an essential component (Nakagawa et al., 2005). These results suggest that HDACIs specifically act on cell death pathways involving the Bax protein but not those that lead to necrosis. 

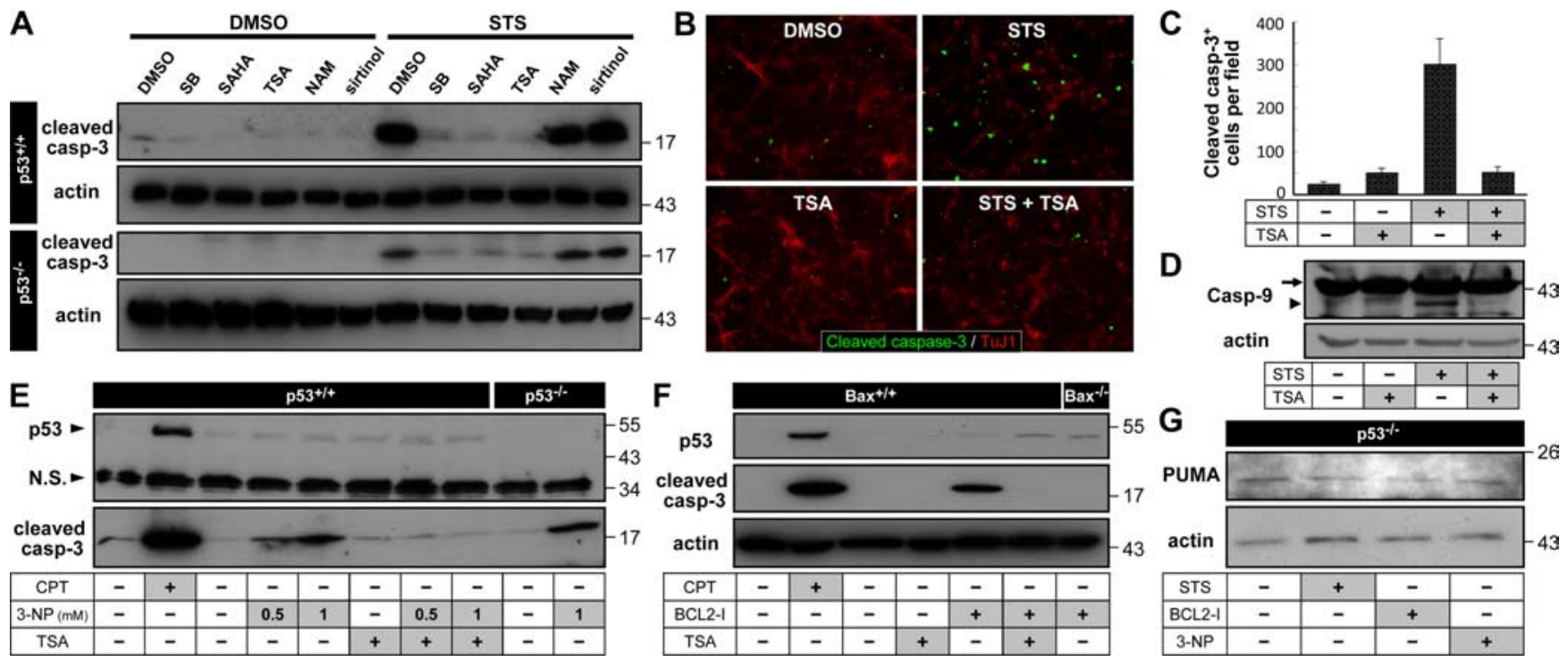

Figure 4. HDACls prevent $\mathrm{p} 53$-independent activation of caspase-3, which occurs independently of PUMA induction. $A, \mathrm{p}^{2} 3^{+/+}$and $\mathrm{p} 53^{-/-}$neurons were treated with staurosporine (STS; 0.5 $\mu \mathrm{m}$ ) in the presence or absence of class I and II HDAC inhibitors (SB, $2 \mathrm{~mm}$; SAHA, $10 \mu \mathrm{m} ; \mathrm{TSA}, 200 \mathrm{~nm}$ ) or sirtuin inhibitors [nicotinamide (NAM), $10 \mathrm{~mm}$; sirtinol, $50 \mu \mathrm{m}$ ]. DMSO was used as a vehicle control. Protein extracts were prepared $8 \mathrm{~h}$ later and analyzed for cleaved caspase-3. Representative data are shown from two independent experiments. $\boldsymbol{B}, \mathrm{p} 53^{-1-}$ neurons treated with STS and/or TSA were fixed $7 \mathrm{~h}$ after treatment and immunostained for cleaved caspase-3 and $\beta$-tubulin III, a neuronal marker (TuJ1 antigen). Representative data are shown from two independent experiments. $C$, The data represent the mean \pm SD of the total number of cleaved caspase-3-positive cells in four random fields within a reticule $(824 \times 660 \mu \mathrm{m})$ from three cultures $(n=3)$. TSA versus TSA plus STS, $p=0.84$; all other combinations are significantly different $(p<0.002-0.05)$. One-way ANOVA using Tukey's post hoc test. $D$, TSA blocks cleavage of caspase-9 induced by STS treatment. $\mathrm{p} 53^{-I-}$ neurons were treated with STS and/or TSA. Protein samples were prepared $7 \mathrm{~h}$ after treatment and analyzed for caspase-9. An arrow and an arrowhead indicate full-length and cleaved caspase-9, respectively. Representative data are shown from two independent experiments. $E$, $\mathrm{p} 53^{+/+}$and $\mathrm{p5} 3^{-1-}$ neurons were treated for $24 \mathrm{~h}$ with $3-\mathrm{NP}$ at the indicated concentrations in the presence or absence of TSA $(200 \mathrm{~nm})$. $p 53^{+/+}$neurons were also treated for $12 \mathrm{~h}$ with (PT to induce p53-dependent caspase- 3 activation. Protein extracts were analyzed for expression of p53 and cleaved caspase-3. The nonspecific bands (N.S.) migrating at $\sim 35 \mathrm{kDa}$ on the p53 blot provide an indication of protein loading. Representative data are shown from three independent experiments. $\boldsymbol{F}, \mathrm{Bax}^{+/+}$and Bax ${ }^{-/-}$neurons were treated for $12 \mathrm{~h}$ with the BCl-2 inhibitor (BCL2-l; $\left.8 \mu \mathrm{M}\right)$ in the presence or absence of TSA. Bax ${ }^{+/+}$neurons were also treated for $12 \mathrm{~h}$ with CPT to induce p53-dependent caspase-3 activation. Protein extracts were analyzed for expression of p53 and cleaved caspase-3. Representative data are shown from two independent experiments. $\boldsymbol{G}$, Protein extracts were prepared from $\mathrm{p}^{-/-}$neurons treated with STS $(0.5 \mu \mathrm{M}, 8 \mathrm{~h}), \mathrm{BCL} 2-\mathrm{I}(8 \mu \mathrm{M}, 12 \mathrm{~h})$, and 3-NP $(1 \mathrm{~mm}, 24 \mathrm{~h})$ and analyzed for expression of PUMA. Representative data are shown from two independent experiments.

Although PUMA is also known as a critical mediator of p53independent Bax activation in response to a variety of stressors, upregulation of PUMA was not seen with the models we tested for p53-independent cell death (Fig. 4G). The apoptotic stimuli we tested did not significantly change the expression levels of Bcl- $\mathrm{x}_{\mathrm{L}}, \mathrm{Bcl}-2$ and Bax (supplemental Fig. $9 B, C$, available at www. jneurosci.org as supplemental material). We then examined the BH3-only proteins, BIM and BID, since these proteins, in addition to PUMA, are able to directly bind and activate the proapoptotic effectors Bax and BAK (Kim et al., 2006; Gavathiotis et al., 2008; Green and Chipuk, 2008). We observed that BID was slightly downregulated by staurosporine and was not affected by TSA (supplemental Fig. 9B, available at www.jneurosci.org as supplemental material). $\mathrm{BIM}_{\mathrm{EL}}$ protein levels were significantly downregulated by staurosporine (supplemental Fig. $9 B$, available at www.jneurosci.org as supplemental material). Interestingly, staurosporine also suppressed the TSA-induced $\mathrm{BIM}_{\mathrm{EL}}$ upregulation down to the level seen with staurosporine alone (supplemental Fig. 9B, available at www.jneurosci.org as supplemental material). This result corroborates that BIM is not involved in p53-independent neuronal cell death induced by staurosporine. Collectively, these results suggest that Bcl- $\mathrm{x}_{\mathrm{L}}, \mathrm{Bcl}-2, \mathrm{Bax}, \mathrm{PUMA}$, BID and BIM do not represent HDACI-sensitive targets in p53independent neuronal apoptosis in cortical neurons. Importantly, upregulation of BIM has been implicated as a mediator of HDACI-dependent cytotoxicity in tumor cells (Zhao et al., 2005). These results suggest that HDACIs block a critical step in the Bax pathway that is distinct from the three known BH3-only proteins capable of directly activating Bax.

\section{Discussion}

The HDACIs have garnered a great deal of attention for their potential therapeutic applications in acute and chronic neurodegenerative diseases. However, very little is known about the mechanisms by which HDACIs promote neuroprotection. In the present study, we sought to identify HDACI-sensitive steps in apoptotic signaling in cultured postnatal mouse cortical neurons. The results demonstrate that (1) HDACIs block p53- and Baxdependent neuronal apoptosis by selectively suppressing p53dependent PUMA expression, (2) HDACIs block p53independent but Bax-dependent neuronal apoptosis, and (3) histone deacetylase activity is a crucial component for transactivation of p53-target genes.

\section{HDACIs confer a general neuroprotective action by blocking} Bax-dependent neuronal apoptosis

Bax plays a critical role in promoting neuronal apoptosis in neurodegeneration (Lindsten et al., 2005). In the present study, we have shown that HDACIs block Bax-dependent caspase- 3 activation both in p53-dependent and p53-independent apoptosis. This result is significant as it may explain why HDACIs exhibit neuroprotection in a wide range of neurodegenerative conditions (Steffan et al., 2001; Petri et al., 2006). This finding naturally points to the importance of focusing on those processes required for all aspects of Bax activation and function to identify specific HDACI-sensitive targets. We identified suppression of PUMA expression by HDACIs as a key event occurring upstream of Bax in p53-dependent apoptosis. HDACI targets in p53-independent apoptosis still remain to be identified. It also remains to be deter- 
mined if HDACIs can block neuronal cell death mediated by the extrinsic apoptotic pathway. If it does block the extrinsic pathway, then suppression of PHLDA3 observed upon HDACI treatment may be involved. We cannot rule out the possibility that HDACIs also directly target the Bax activation step itself including 6A7 epitope exposure, mitochondrial translocation and oligomerization. This could be the case in p53-independent/Baxdependent apoptosis, for which we were unable to find an HDACI-sensitive target among several likely candidates of Bcl-2 family members. The Bax-Ku70 interaction, which prevents mitochondrial translocation of Bax, is one such mechanism. This mechanism is unlikely to account for the neuroprotective action of HDACIs in primary cortical neurons, however, as HDACIinduced acetylation of Ku70 activates apoptosis by permitting Bax release from Ku70 promoting its mitochondrial translocation (Cohen et al., 2004; Subramanian et al., 2005).

\section{The p53 transcriptional complex in neurons requires histone deacetylase activity to induce apoptosis}

Our results involving HDACI removal in the presence of transcription/translation inhibitors suggest that transcriptional events must be a site where HDAC activity is required in CPTinduced p53-dependent apoptosis, consistent with our previous report demonstrating that p53 transcriptional activity is indispensable in this apoptosis model (Uo et al., 2007). The results also indicated that, to produce a neuroprotective effect, HDACIs must block p53/HDAC-dependent induction of proapoptotic genes rather than induce antiapoptotic genes. This observation is consistent with the lack of change in $\mathrm{Bcl}-2$ or $\mathrm{Bcl}-\mathrm{x}_{\mathrm{L}}$ expression after HDACI treatment. Accordingly, p53-dependent induction of PUMA, a critical mediator of p53-dependent neuronal apoptosis (Uo et al., 2007), was identified as a target of HDACI action upstream of Bax activation. The expression of PUMA was almost completely dependent on both p53 and HDAC activity, and PUMA mRNA induction subsequent to HDACI removal in CPTtreated neurons did not require new protein synthesis. These results suggest that HDACIs directly target the activity of the p53-dependent PUMA transcriptional complex. The involvement of other p53-inducible proapoptotic genes thus appears to be minimal, although the requirement for PUMA (Cregan et al., 2004; Wong et al., 2005; Uo et al., 2007) may mask the contribution of other HDACI-sensitive targets.

The transcriptional function of $\mathrm{p} 53$ is directly regulated by the HAT/HDAC system. Three classes of HATs (p300/CBP, p300/ CBP-associated factor and hMOF/Tip60) acetylate p53 and enhance its stability and transcriptional activity (Kruse and $\mathrm{Gu}$, 2008). HDACs conversely deacetylate p53 making lysine residues available for other modifications. In the context of our neuronal apoptosis model, increased levels of p53 accumulating in response to HDACI treatment is presumably incapable of either binding to the p53-responsive element of the PUMA gene or recruiting the necessary cofactors needed to ensure transcriptional activation. Although p53 acetylation generally promotes its transactivational activity, the outcome depends on which p53 lysine residues and promoters are specifically involved. Acetylation of K317 (K320 in human) negatively regulates p53's apoptotic activity in response to DNA damage (Chao et al., 2006; Knights et al., 2006). Thus, p53's apoptotic transcriptional activity can be modified and potentially inhibited by augmenting acetylation of this specific lysine residue. We have shown that HDACI treatment enhances accumulation of DNA damage-induced p53, suggesting p53 hyperacetylation. If increased acetylation also targets this "apoptosis-suppressive" lysine residue, it would limit p53 function in the otherwise active p53 transcriptional complex on the PUMA promoter. Indeed, PUMA and PHDLA3, whose DNA damage-induced upregulation was compromised by HDACI treatment, represent major proapoptotic p53 targets that are negatively regulated by $\mathrm{K} 317$ acetylation (Chao et al., 2006). The contribution of $\mathrm{K} 317$ acetylation in our neuronal model is not known. K317 acetylation was shown to promote p53 retention in the cytoplasm (Knights et al., 2006), which we did not observe in CPT/HDACI-treated neurons. Therefore, there may be additional p53 lysine residues whose acetylation mitigates p53-dependent transcription in neurons.

Alternatively, HDACIs may not directly target p53 acetylation but rather cofactors participating in PUMA transcriptional control. Although HDACs generally act as corepressors, they are also implicated in the transactivation of certain genes (Cho et al., 2005; Nusinzon and Horvath, 2005), and HDAC1 may specifically show such activity (Zupkovitz et al., 2006). A recent study with steroid receptor-induced gene expression (Qiu et al., 2006) provides some mechanistic insights. This finding revealed that deacetylated and enzymatically active HDAC1 coactivates, whereas acetylated and, therefore, inactive HDAC1 represses the target promoter activity. If $\mathrm{HDAC} 1$, which is known to interact with p53 (Luo et al., 2000), is recruited to the PUMA promoter and behaves similarly, HDACI-induced inhibition of HDAC1 may result in repression of PUMA expression.

\section{Unique modes of HDACI action in neurons}

The antiapoptotic action of HDACIs we observed in neurons is relatively uncommon and contrasts with their proapoptotic actions more ubiquitously observed in tumor cells (Bolden et al., 2006; Dokmanovic et al., 2007). It is not clear if this represents a neuron-specific or a promoter-specific event. There are several features of apoptosis that appear to be unique to cortical neurons. Bax is the sole mediator of mitochondrial apoptosis in these cells (Uo et al., 2005), and p53 does not exert a direct apoptotic action in mitochondria/cytoplasm as reported for many non-neuronal cells (Moll et al., 2005). Moreover, PUMA represents a critical mediator of p53-dependent apoptosis among the large family of BH3-only proteins (Youle and Strasser, 2008). The effect of HDACIs on the p53-dependent apoptotic pathway appears to largely depend on whether NOXA exerts proapoptotic activity in any given cell type since it is not suppressed by HDACIs. It is conceivable that HDACI treatment may also block Baxdependent cell death in non-neuronal cells, but it may not promote protection as the simultaneous presence of BAK could mediate apoptotic signaling, in contrast to neurons, via the activation of multiple $\mathrm{BH} 3$-only proteins. HDACI-mediated inhibition of PUMA induction also occurs in some non-neuronal cells as we demonstrated here, although cells may die in response to the upregulation of other apoptotic proteins such as NOXA and PIG3 (Terui et al., 2003). This suggests that the transcriptional complex for the PUMA promoter may contain a unique HDACI-sensitive feature in some cell types including neurons. Thus, to selectively manipulate p53's proapoptotic transcriptional activities by HDACIs (inhibition for neurons and augmentation for tumor cells), it is critical to eventually determine the specific pattern of p53 acetylation and the composition of the specific promoters including HAT and HDAC species.

Another unexpected finding was the variable effect that HDACIs had on the expression of $\mathrm{BH} 3$-only proteins. In contrast to PUMA suppression, HDACI treatment upregulated BIM in neurons although this was not associated with apoptosis. Upregulation of BIM has been implicated as a mediator of HDACI- 
dependent apoptosis in tumor cells (Zhao et al., 2005). Cortical neurons are responsive to BIM's apoptotic action since BIM expression itself was capable of causing neuronal death in a Baxdependent manner (supplemental Fig. 6C, available at www. jneurosci.org as supplemental material). Thus, HDACI must be capable of blocking this self-induced BIM activity in a neuronspecific manner. This "BIM-neutralizing" activity associated with HDACIs in cortical neurons and potentially in other neuronal types may have significant implications for neurodegenerative disease therapies as BIM upregulation has been demonstrated to be a critical contributor to neuronal death in Alzheimer's disease (Biswas et al., 2007), Parkinson's disease (Perier et al., 2007) and ALS (Hetz et al., 2007).

In summary, the present study demonstrates that HDACIs can suppress both p53-dependent and p53-independent biochemical pathways activated during the course of neuronal apoptosis and converging on Bax but involving distinct apoptosis mediators as HDACI targets. The finding that the p53-PUMABax pathway is a novel target of HDACIs also indicates an unexpected role for HDAC activity in the transactivation of p53-target genes. Identification of the specific HDAC(s) involved in this process provides a rationale strategy for treating brain injury and diseases.

\section{References}

Bae BI, Xu H, Igarashi S, Fujimuro M, Agrawal N, Taya Y, Hayward SD, Moran TH, Montell C, Ross CA, Snyder SH, Sawa A (2005) p53 mediates cellular dysfunction and behavioral abnormalities in Huntington's disease. Neuron 47:29-41.

Biswas SC, Shi Y, Vonsattel JP, Leung CL, Troy CM, Greene LA (2007) Bim is elevated in Alzheimer's disease neurons and is required for $\beta$-amyloidinduced neuronal apoptosis. J Neurosci 27:893-900.

Bolden JE, Peart MJ, Johnstone RW (2006) Anticancer activities of histone deacetylase inhibitors. Nat Rev Drug Discov 5:769-784.

Chao C, Wu Z, Mazur SJ, Borges H, Rossi M, Lin T, Wang JY, Anderson CW, Appella E, Xu Y (2006) Acetylation of mouse p53 at lysine 317 negatively regulates p53 apoptotic activities after DNA damage. Mol Cell Biol 26:6859-6869.

Cho Y, Griswold A, Campbell C, Min KT (2005) Individual histone deacetylases in Drosophila modulate transcription of distinct genes. Genomics 86:606-617.

Cohen HY, Lavu S, Bitterman KJ, Hekking B, Imahiyerobo TA, Miller C, Frye R, Ploegh H, Kessler BM, Sinclair DA (2004) Acetylation of the C terminus of Ku70 by CBP and PCAF controls Bax-mediated apoptosis. Mol Cell 13:627-638.

Cregan SP, Arbour NA, Maclaurin JG, Callaghan SM, Fortin A, Cheung EC, Guberman DS, Park DS, Slack RS (2004) p53 activation domain 1 is essential for PUMA upregulation and p53-mediated neuronal cell death. J Neurosci 24:10003-10012.

Doi S, Soda H, Oka M, Tsurutani J, Kitazaki T, Nakamura Y, Fukuda M, Yamada Y, Kamihira S, Kohno S (2004) The histone deacetylase inhibitor FR901228 induces caspase-dependent apoptosis via the mitochondrial pathway in small cell lung cancer cells. Mol Cancer Ther 3:1397-1402.

Dokmanovic M, Clarke C, Marks PA (2007) Histone deacetylase inhibitors: overview and perspectives. Mol Cancer Res 5:981-989.

Enyedy IJ, Ling Y, Nacro K, Tomita Y, Wu X, Cao Y, Guo R, Li B, Zhu X, Huang Y, Long YQ, Roller PP, Yang D, Wang S (2001) Discovery of small-molecule inhibitors of Bcl-2 through structure-based computer screening. J Med Chem 44:4313-4324.

Ferrante RJ, Kubilus JK, Lee J, Ryu H, Beesen A, Zucker B, Smith K, Kowall NW, Ratan RR, Luthi-Carter R, Hersch SM (2003) Histone deacetylase inhibition by sodium butyrate chemotherapy ameliorates the neurodegenerative phenotype in Huntington's disease mice. J Neurosci 23:9418-9427.

Gardian G, Browne SE, Choi DK, Klivenyi P, Gregorio J, Kubilus JK, Ryu H, Langley B, Ratan RR, Ferrante RJ, Beal MF (2005) Neuroprotective effects of phenylbutyrate in the N171-82Q transgenic mouse model of Huntington's disease. J Biol Chem 280:556-563.
Gavathiotis E, Suzuki M, Davis ML, Pitter K, Bird GH, Katz SG, Tu HC, Kim H, Cheng EH, Tjandra N, Walensky LD (2008) BAX activation is initiated at a novel interaction site. Nature 455:1076-1081.

Green DR, Chipuk JE (2008) Apoptosis: stabbed in the BAX. Nature 455: 1047-1049.

Hajji N, Wallenborg K, Vlachos P, Nyman U, Hermanson O, Joseph B (2008) Combinatorial action of the HDAC inhibitor trichostatin A and etoposide induces caspase-mediated AIF-dependent apoptotic cell death in nonsmall cell lung carcinoma cells. Oncogene 27:3134-3144.

Harris CA, Johnson EM Jr (2001) BH3-only Bcl-2 family members are coordinately regulated by the JNK pathway and require Bax to induce apoptosis in neurons. J Biol Chem 276:37754-37760.

Hetz C, Thielen P, Fisher J, Pasinelli P, Brown RH, Korsmeyer S, Glimcher L (2007) The proapoptotic BCL-2 family member BIM mediates motoneuron loss in a model of amyotrophic lateral sclerosis. Cell Death Differ 14:1386-1389.

Hockly E, Richon VM, Woodman B, Smith DL, Zhou X, Rosa E, Sathasivam K, Ghazi-Noori S, Mahal A, Lowden PA, Steffan JS, Marsh JL, Thompson LM, Lewis CM, Marks PA, Bates GP (2003) Suberoylanilide hydroxamic acid, a histone deacetylase inhibitor, ameliorates motor deficits in a mouse model of Huntington's disease. Proc Natl Acad Sci U S A 100:2041-2046.

Jen KY, Cheung VG (2005) Identification of novel p53 target genes in ionizing radiation response. Cancer Res 65:7666-7673.

Johnson MD, Kinoshita Y, Xiang H, Ghatan S, Morrison RS (1999) Contribution of p53-dependent caspase activation to neuronal cell death declines with neuronal maturation. J Neurosci 19:2996-3006.

Kim H, Rafiuddin-Shah M, Tu HC, Jeffers JR, Zambetti GP, Hsieh JJ, Cheng EH (2006) Hierarchical regulation of mitochondrion-dependent apoptosis by BCL-2 subfamilies. Nat Cell Biol 8:1348-1358.

Knights CD, Catania J, Di Giovanni S, Muratoglu S, Perez R, Swartzbeck A, Quong AA, Zhang X, Beerman T, Pestell RG, Avantaggiati ML (2006) Distinct p53 acetylation cassettes differentially influence gene-expression patterns and cell fate. J Cell Biol 173:533-544.

Kruse JP, Gu W (2008) SnapShot: P53 posttranslational modifications. Cell 133:930-930.e1.

Langley B, D’Annibale MA, Suh K, Ayoub I, Tolhurst A, Bastan B, Yang L, Ko B, Fisher M, Cho S, Beal MF, Ratan RR (2008) Pulse inhibition of histone deacetylases induces complete resistance to oxidative death in cortical neurons without toxicity and reveals a role for cytoplasmic p21(wafl/ cip1) in cell cycle-independent neuroprotection. J Neurosci 28:163-176.

Lindsten T, Zong WX, Thompson CB (2005) Defining the role of the Bcl-2 family of proteins in the nervous system. Neuroscientist 11:10-15.

Luo J, Su F, Chen D, Shiloh A, Gu W (2000) Deacetylation of p53 modulates its effect on cell growth and apoptosis. Nature 408:377-381.

Minamiyama M, Katsuno M, Adachi H, Waza M, Sang C, Kobayashi Y, Tanaka F, Doyu M, Inukai A, Sobue G (2004) Sodium butyrate ameliorates phenotypic expression in a transgenic mouse model of spinal and bulbar muscular atrophy. Hum Mol Genet 13:1183-1192.

Moll UM, Wolff S, Speidel D, Deppert W (2005) Transcriptionindependent pro-apoptotic functions of p53. Curr Opin Cell Biol 17:631-636.

Morris EJ, Keramaris E, Rideout HJ, Slack RS, Dyson NJ, Stefanis L, Park DS (2001) Cyclin-dependent kinases and P53 pathways are activated independently and mediate Bax activation in neurons after DNA damage. J Neurosci 21:5017-5026.

Morrison RS, Kinoshita Y, Johnson MD, Guo W, Garden GA (2003) p53dependent cell death signaling in neurons. Neurochem Res 28:15-27.

Nakagawa T, Shimizu S, Watanabe T, Yamaguchi O, Otsu K, Yamagata H, Inohara H, Kubo T, Tsujimoto Y (2005) Cyclophilin D-dependent mitochondrial permeability transition regulates some necrotic but not apoptotic cell death. Nature 434:652-658.

Nusinzon I, Horvath CM (2005) Histone deacetylases as transcriptional activators? Role reversal in inducible gene regulation. Sci STKE 2005:re11.

Park CG, Lee SY, Kandala G, Lee SY, Choi Y (1996) A novel gene product that couples TCR signaling to Fas(CD95) expression in activationinduced cell death. Immunity 4:583-591.

Perier C, Bové J, Wu DC, Dehay B, Choi DK, Jackson-Lewis V, RathkeHartlieb S, Bouillet P, Strasser A, Schulz JB, Przedborski S, Vila M (2007) Two molecular pathways initiate mitochondria-dependent dopaminergic neurodegeneration in experimental Parkinson's disease. Proc Natl Acad Sci U S A 104:8161-8166. 
Petri S, Kiaei M, Kipiani K, Chen J, Calingasan NY, Crow JP, Beal MF (2006) Additive neuroprotective effects of a histone deacetylase inhibitor and a catalytic antioxidant in a transgenic mouse model of amyotrophic lateral sclerosis. Neurobiol Dis 22:40-49.

Qiu Y, Zhao Y, Becker M, John S, Parekh BS, Huang S, Hendarwanto A, Martinez ED, Chen Y, Lu H, Adkins NL, Stavreva DA, Wiench M, Georgel PT, Schiltz RL, Hager GL (2006) HDAC1 acetylation is linked to progressive modulation of steroid receptor-induced gene transcription. Mol Cell 22:669-679.

Riedl SJ, Salvesen GS (2007) The apoptosome: signalling platform of cell death. Nat Rev Mol Cell Biol 8:405-413.

Ryu H, Smith K, Camelo SI, Carreras I, Lee J, Iglesias AH, Dangond F, Cormier KA, Cudkowicz ME, Brown RH Jr, Ferrante RJ (2005) Sodium phenylbutyrate prolongs survival and regulates expression of antiapoptotic genes in transgenic amyotrophic lateral sclerosis mice. J Neurochem 93:1087-1098.

Saha RN, Pahan K (2006) HATs and HDACs in neurodegeneration: a tale of disconcerted acetylation homeostasis. Cell Death Differ 13:539-550.

Steffan JS, Bodai L, Pallos J, Poelman M, McCampbell A, Apostol BL, Kazantsev A, Schmidt E, Zhu YZ, Greenwald M, Kurokawa R, Housman DE, Jackson GR, Marsh JL, Thompson LM (2001) Histone deacetylase inhibitors arrest polyglutamine-dependent neurodegeneration in Drosophila. Nature 413:739-743

Subramanian C, Opipari AW Jr, Bian X, Castle VP, Kwok RP (2005) Ku70 acetylation mediates neuroblastoma cell death induced by histone deacetylase inhibitors. Proc Natl Acad Sci U S A 102:4842-4847.

Terui T, Murakami K, Takimoto R, Takahashi M, Takada K, Murakami T, Minami S, Matsunaga T, Takayama T, Kato J, Niitsu Y (2003) Induction of PIG3 and NOXA through acetylation of p53 at 320 and 373 lysine residues as a mechanism for apoptotic cell death by histone deacetylase inhibitors. Cancer Res 63:8948-8954.

Uo T, Kinoshita Y, Morrison RS (2005) Neurons exclusively express N-Bak, a BH3 domain-only Bak isoform that promotes neuronal apoptosis. J Biol Chem 280:9065-9073.
Uo T, Kinoshita Y, Morrison RS (2007) Apoptotic actions of p53 require transcriptional activation of PUMA and do not involve a direct mitochondrial/cytoplasmic site of action in postnatal cortical neurons. J Neurosci 27:12198-12210

Vassilev LT, Vu BT, Graves B, Carvajal D, Podlaski F, Filipovic Z, Kong N, Kammlott U, Lukacs C, Klein C, Fotouhi N, Liu EA (2004) In vivo activation of the 553 pathway by small-molecule antagonists of MDM2. Science 303:844-848.

Vousden KH, Lane DP (2007) p53 in health and disease. Nat Rev Mol Cell Biol 8:275-283.

Wong HK, Fricker M, Wyttenbach A, Villunger A, Michalak EM, Strasser A, Tolkovsky AM (2005) Mutually exclusive subsets of BH3-only proteins are activated by the p53 and c-Jun N-terminal kinase/c-Jun signaling pathways during cortical neuron apoptosis induced by arsenite. Mol Cell Biol 25:8732-8747.

Xiang H, Hochman DW, Saya H, Fujiwara T, Schwartzkroin PA, Morrison RS (1996) Evidence for p53-mediated modulation of neuronal viability. J Neurosci 16:6753-6765.

Xiang H, Kinoshita Y, Knudson CM, Korsmeyer SJ, Schwartzkroin PA, Morrison RS (1998) Bax involvement in p53-mediated neuronal cell death. J Neurosci 18:1363-1373.

Yakovlev AG, Di Giovanni S, Wang G, Liu W, Stoica B, Faden AI (2004) BOK and NOXA are essential mediators of p53-dependent apoptosis. J Biol Chem 279:28367-28374.

Youle RJ, Strasser A (2008) The BCL-2 protein family: opposing activities that mediate cell death. Nat Rev Mol Cell Biol 9:47-59.

Zhao Y, Tan J, Zhuang L, Jiang X, Liu ET, Yu Q (2005) Inhibitors of histone deacetylases target the Rb-E2F1 pathway for apoptosis induction through activation of proapoptotic protein Bim. Proc Natl Acad Sci U S A 102:16090-16095.

Zupkovitz G, Tischler J, Posch M, Sadzak I, Ramsauer K, Egger G, Grausenburger R, Schweifer N, Chiocca S, Decker T, Seiser C (2006) Negative and positive regulation of gene expression by mouse histone deacetylase 1 . Mol Cell Biol 26:7913-7928. 